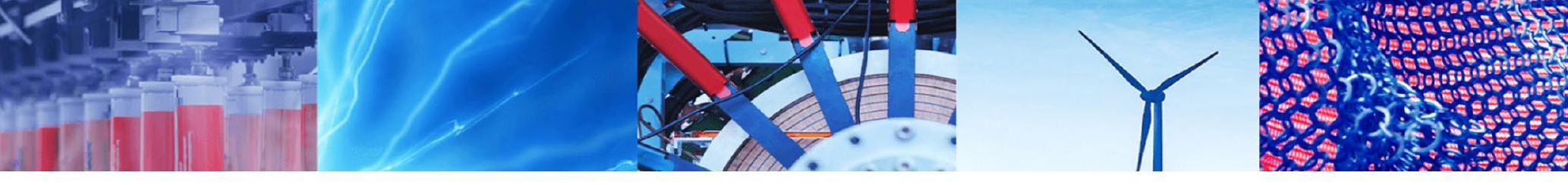

Case Study

\title{
Influence of short-time thermal ageing on the behaviour of double lap composite adhesively bonded joints
}

\author{
Joseph El Hage ${ }^{1} \cdot$ Georges Challita ${ }^{1}$ (D) Julien Capelle ${ }^{2} \cdot J^{\prime}$ oseph Gilgert ${ }^{2} \cdot$ Akram Alhussein $^{3}$
}

Received: 19 June 2020 / Accepted: 14 September 2020 / Published online: 24 September 2020

(c) Springer Nature Switzerland AG 2020

\begin{abstract}
Double lap bonded glass-epoxy composite assemblies were tested under static and cyclic shear condition loading where the static shear strength and the number of cycles to failure were measured, respectively. Araldite 2031 epoxy was the adhesive used having a glass transition temperature of $65^{\circ} \mathrm{C}$. In order to verify the influence of the thermal ageing on the adhesive behaviour, three different thermal treatments of the assemblies were adopted: one below the glass temperature (unaged) and 2 aged for 1 and 2 weeks, respectively, at $10^{\circ} \mathrm{C}$ above the glass temperature. It was found that the latter case has shown the highest shear strength and number of cycles to failure. Scanning electron microscopy analyses of the adhesive-substrate interfaces for the three ageing configurations have shown best adherence for the 2-week aged specimens. Moreover, series of thermal stability analyses of the adhesive picked up from the fractured specimens from the three types of ageing have confirmed the results: thermogravimetric analysis has shown that the degradation temperature was not reached during any of the adopted thermal ageing configurations, while differential scanning calorimetry has spotted on the stability status of the adhesive pointing out the improvement in morphology and even the increment of transition temperature, and finally Fourier transform infrared spectroscopy analysis has confirmed the absence of oxidation of the adhesive under all ageing configurations.
\end{abstract}

Keywords Adhesive joint · Thermal ageing · Shear strength · Life cycle · Thermal analysis

\section{Introduction}

The increasing usage of durable lightweight structures has driven the scientific community to search for an alternative to the high density steel and replace it either with aluminium or with the continuously evolving composite materials. However, a main setback is still present as the most common joining methods are welding and bolting, which create weak points (heat-affected zone for welding and stress concentration at holes for bolting). Adhesive bonding, on the other hand, offers a wider area for stress distribution and reduces the time and costs of fabrication. In addition, this joining technique seems to be convenient for composite assembling where drilling and disrupting are avoided [1-3].

Nowadays, adhesive joints have a wide range of applications where they are exposed to extreme conditions. It is essential for the adhesive to keep its mechanical properties and maintain a good static and fatigue resistance during the service life. Generally, adhesives are thermoset polymers; thus, they are sensitive to temperature variations; this influences the behaviour of the whole bonded structure.

Many works were interested in investigating aged adhesively bonded structures under static loading. Dissimilar steel-FRP composite double lap joints were tested under

$\triangle$ Georges Challita, georges.challita@ul.edu.lb| ${ }^{1}$ Faculty of Engineering, Equipe MMC, CRSI, Lebanese University, Roumieh, El-Metn, Lebanon. ${ }^{2}$ LaBPS—ENIM, 1 route d'Ars Laquenexy, CS 65820, 57078 Metz, France. ${ }^{3}$ ICD—LASMIS, CNRS, Pôle Technologique de Sud-Champagne, Université de Technologie de Troyes, 52800 Nogent, France. 
various severe environmental conditions up to 3 years by Heshmati et al. [4]; they found that the strength and the stiffness of specimens with glass fibre reinforced polymer (GFRP) dropped more considerably than those involving carbon fibre reinforced polymer (CFRP). They checked also by finite element simulations the moisture distribution at the adhesive-substrate interface. Stazi et al. [5] were concerned by comparing six different types of adhesives in single lap joint (SLJ) and butt-joint GFRP composite bonded joints subjected to hygrothermal variation and UV light exposure, separately. The carrying load was found to change slightly while the stiffness reduction was considerable. Nguyen et al. [6] were also interested in dissimilar steel-CFRP double strap joint in a range of temperatures from $20^{\circ} \mathrm{C}$ to $60^{\circ} \mathrm{C}$ involving the adhesive's glass transition temperature. They observed a change in failure mode before and after this temperature; also they noticed a drop in carrying load and joint stiffness. They modelled the effective bond length and mechanical degradation, based on the Hart-Smith model. The same substrates were used by Agarwal et al. [7] to test single lap joint assemblies under dry and wet conditions, subjected to a temperature range between $10^{\circ} \mathrm{C}$ and $50^{\circ} \mathrm{C}$. They concluded that the adhesive must have a glass transition temperature $30^{\circ} \mathrm{C}$ above the operating temperature to avoid failure of the joint. Jeong et al. [8] examined the behaviour of single lap joint carbon/epoxy bonded joints under many humidity conditions for both tap and salt water and this for room temperature as well as $71{ }^{\circ} \mathrm{C}$. Akderya et al. [9] tested SLJ composite joints under impact loading for three different ageing temperatures: $-18{ }^{\circ} \mathrm{C}, 25^{\circ} \mathrm{C}$ and $70{ }^{\circ} \mathrm{C}$ and their effect on the tensile properties; the lowest temperature has shown a positive effect towards load capacity. Composite joints for automotive applications were the main concern of Machado et al. [10]; they investigated under both static and impact loading single lap adhesively CFRP composite assemblies with a ductile crash-resistant epoxy and this under a wide range of temperatures: $-30^{\circ} \mathrm{C}, 24^{\circ} \mathrm{C}$ and $80^{\circ} \mathrm{C}$. Also two different overlap lengths were examined: 12.5 and $25 \mathrm{~mm}$.

There are only few papers examining the effect of the temperature on fatigue behaviour of bonded assemblies. Wang et al. [11] examined the effect of the hot humid environmental exposure prior to and after adhesive curing on the fatigue crack growth (FCG) behaviour of adhesive-bonded aluminium A356 joints. FCG has been investigated by using single end notched bending specimen. The main results were that the environmental exposure prior to adhesive curing has relatively small influence on the FCG behaviour of adhesive-bonded aluminium A356 joints, but the environmental exposure after adhesive curing significantly deteriorates the FCG resistances of the joints. One may also cite the work of Ashcroft et al. [12] who measured the strength under both static and fatigue loading of double lap FRP composite joints in an interval of temperatures experienced by a jet aircraft. Multidirectional and unidirectional composites were compared. They found a decrease in the strength with the operating temperature. Ferreira et al. [13] determined the number of cycles to failure for single lap joint where the substrates were E-glass woven fabric with polypropylene matrix and examined the effect of many parameters such as the layer orientation, the overlap length and the temperature of the water immersing the specimens. Fernandes et al. [14] studied pure modes I and II fracture of epoxy bonded CFRP joints at $0^{\circ} \mathrm{C}, 25^{\circ} \mathrm{C}$ and $50^{\circ} \mathrm{C}$. They concluded that the fracture behaviour under mode I loading is not affected in the range of $0{ }^{\circ} \mathrm{C}-25^{\circ} \mathrm{C}$ but was markedly influenced at $50^{\circ} \mathrm{C}$ which was attributed to the proximity with the glass transition temperature of the adhesive. In contrast, the shear fracture response revealed to be almost uninfluenced in the global range of the analyzed temperature. Hu et al. [15] applied a cyclic thermal load between $-30^{\circ} \mathrm{C}$ and $80^{\circ} \mathrm{C}$ on aluminium single lap joint as environmental condition and defined a cohesive zone model (CZM) to predict damage. Stress states before and after exposure were determined. Zhang et al. [16] tested the fatigue behaviour of adhesively bonded pultruded GFRP double lap joint at $-35^{\circ} \mathrm{C}, 23^{\circ} \mathrm{C}$ and $40^{\circ} \mathrm{C}$. They concluded that increased temperature seems to shorten specimen fatigue life. Sousa et al. [17] compared epoxy and polyurethane adhesives used in GFRP single lap joints subjected to thermal cycles between $-5^{\circ} \mathrm{C}$ and $40^{\circ} \mathrm{C}$, both have shown similar behaviour towards stiffness reduction and failure mechanisms. Fatigue failure of scarf joints constituted the main concern of Schneider et al. [18] who tested those assemblies under both constant and variable stress amplitudes at temperatures of $-10^{\circ} \mathrm{C}, 23^{\circ} \mathrm{C}$ and $50^{\circ} \mathrm{C}$. All thermal ageing periods in the cited works were either long-period, cyclic or simultaneous with the mechanical testing.

Globally, either very long duration or cyclic thermal ageing have been selected in the literature. In the present work, and for comparative purpose, three short-time thermal ageing temperatures were adopted and applied to unidirectional (UD) glass-epoxy double lap bonded joint: ambient temperature, $75^{\circ} \mathrm{C}$ at 1 week and $75^{\circ} \mathrm{C}$ at 2 weeks. Then static and cyclic shear loading tests were performed where the static shear strength and the number of cycles to failure under a constant axial imposed force were, respectively, measured. It was found that the most aged specimens have shown higher shear strength and fatigue life. SEM observation of the fractured interfaces and then a complete thermal analysis of the Araldite 2031 Epoxy adhesive picked up from the fractured specimens were performed and have led to an interpretation of the obtained results. 


\section{Experimental analysis}

\subsection{Double lap specimen}

Specimens had double lap joint (DLJ) geometry (Fig. 1) and were prepared from plates made of unidirectional (UD) glass-epoxy laminate (E-glass prepreg, Delta preg, $\left.V_{f}=60 \%\right)$ at Balamand University in the North of Lebanon where lamina mechanical properties were measured experimentally. They are presented in Table 1. The upper and lower plates were $2.35 \mathrm{~mm}$ thick each, while the middle plate had a thickness of $4.7 \mathrm{~mm}$. The adherents were cut from the plates considering nominal length and width of 100 and $30 \mathrm{~mm}$, respectively. The surfaces of the adherents were rough by production and were cleaned with acetone. Two-part (50\% resin-50\% hardener) ductile epoxy adhesive, trade name Araldite ${ }^{\oplus}$ 2031 (produced by Huntsman [19] $-E=1000 \mathrm{MPa}$; $v=0.4$ ), was used as bonding material. All specimens had an overlap of $50 \mathrm{~mm}$ with about $1 \mathrm{~mm}$ variability. The adhesive layer thickness of $0.3 \mathrm{~mm}$ was assured using calibrated steel spacers between the adherents and a rectangular thick steel pressure plate to apply uniform pressure on the bonded surfaces during the curing process. In-plane alignment of the substrates was ensured through studs connected to the base plate. According to the manufacturer Huntsman [19], a 24-h room temperature cure cycle would be enough for the adhesive curing process.
Table 1 Elastic properties of GFRP. Directions: 1-longitudinal, 2-transversal, 3-thickness

\begin{tabular}{llllll}
\hline Property & $E_{1}(\mathrm{MPa})$ & $E_{2}(\mathrm{MPa})$ & $G_{12}(\mathrm{MPa})$ & $G_{13}(\mathrm{MPa})$ & $v_{12}$ \\
\hline Value & 44,000 & 9000 & 4500 & 4500 & 0.2 \\
\hline
\end{tabular}

\subsection{Static loading tests}

The tensile tests were performed at room temperature using a universal testing machine equipped with load cell of $300 \mathrm{kN}$. A loading displacement rate of $5 \mathrm{~mm} / \mathrm{min}$ was applied, and the load-displacement $(P-\delta)$ curve was registered during the test. Five samples of each ageing condition were tested and analyzed to record reliable measurements of the joint's strength. Figure 2 shows a specimen mounted on the tensile testing machine and the same specimen during adhesive failure.

All specimens failed similarly, with different maximum loads. The load-deformation curve (Fig. 3) shows the brittle behaviour of the adhesively bonded DLJs with the lack of any apparent plasticity zone. The trend of the increasing maximum load with the increasing thermal ageing duration could be observed in Table 2. Moreover, this table illustrates the axial displacement of the middle adherent at failure.

\subsection{Cyclic loading tests}

Five specimens from each thermal ageing configuration were tested under axial tensile force (which mainly
Fig. 1 Side view of a specimen (top), schematic representation of the joint (bottom)
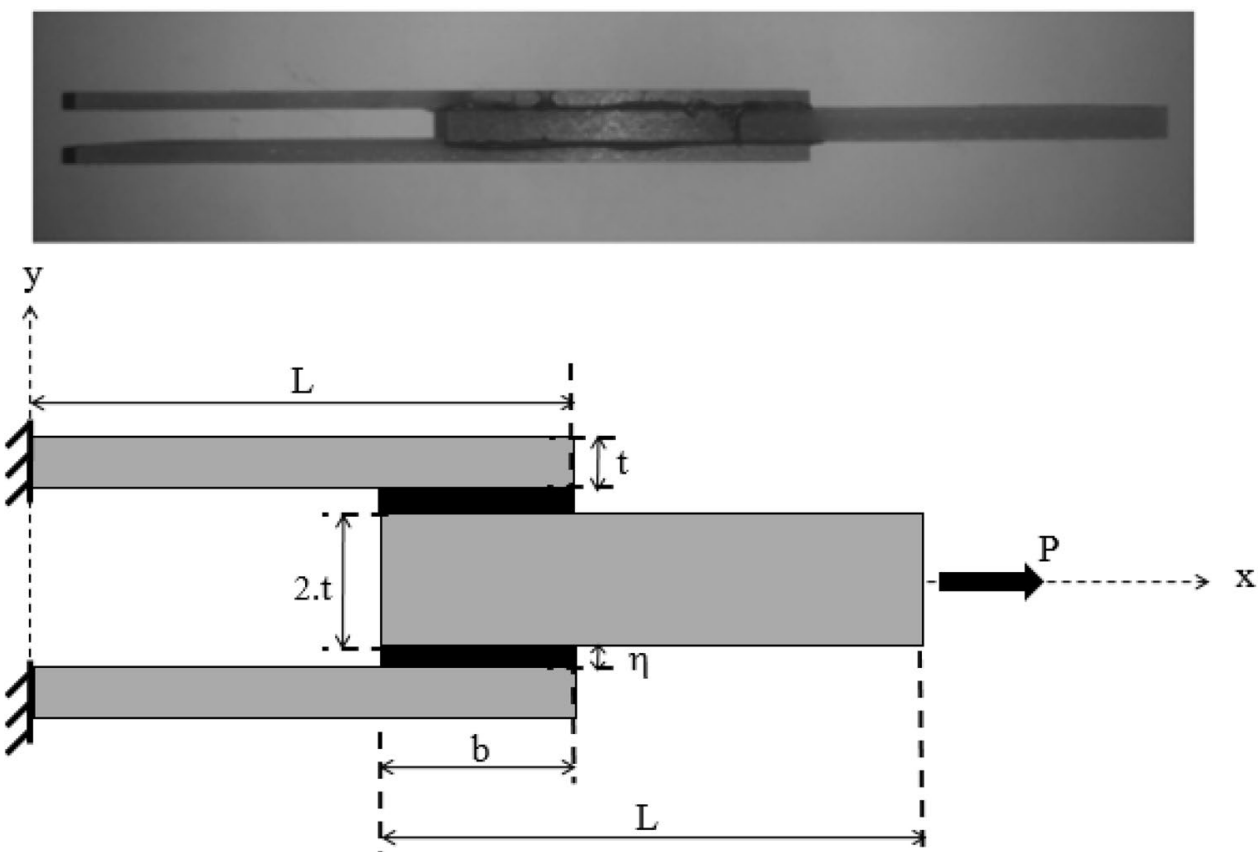
Fig. 2 a Specimen before tensile testing, b specimen failure and layer separation

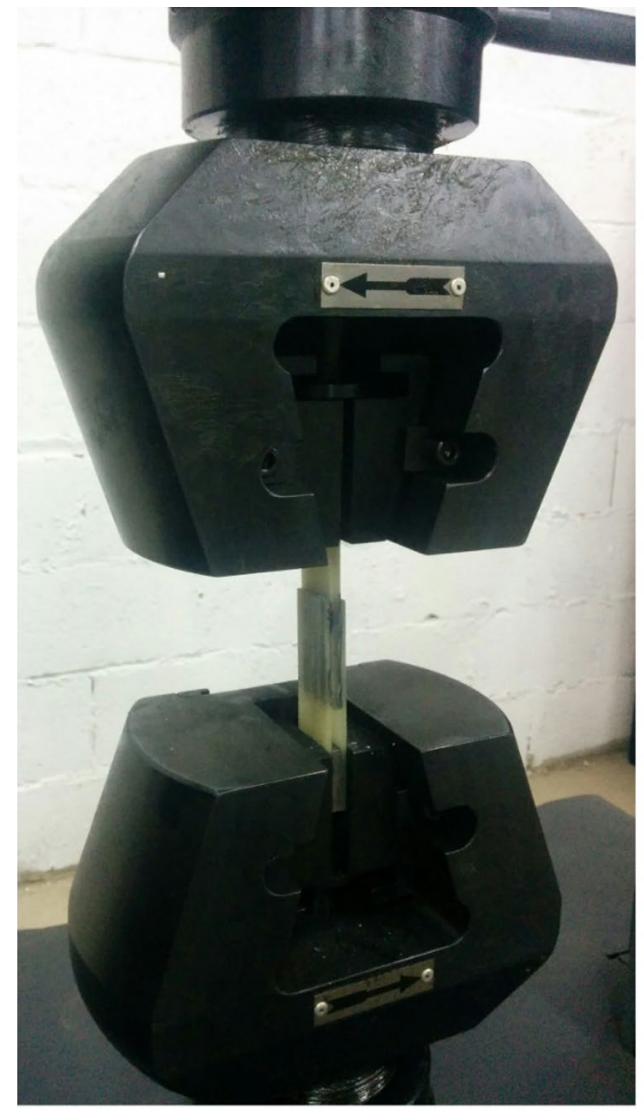

(a)

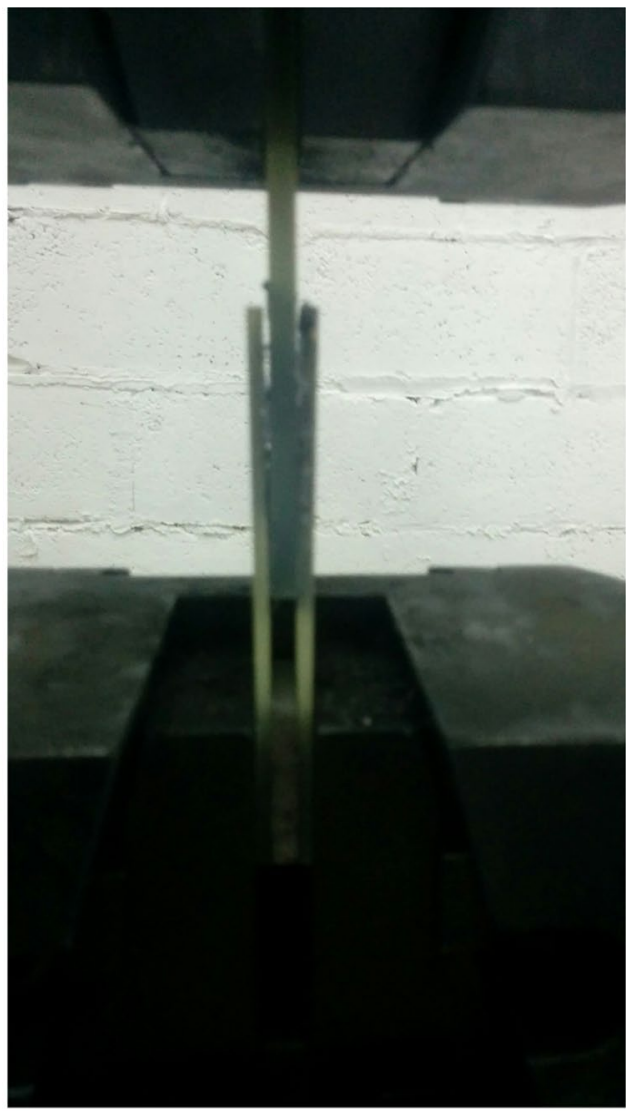

(b)

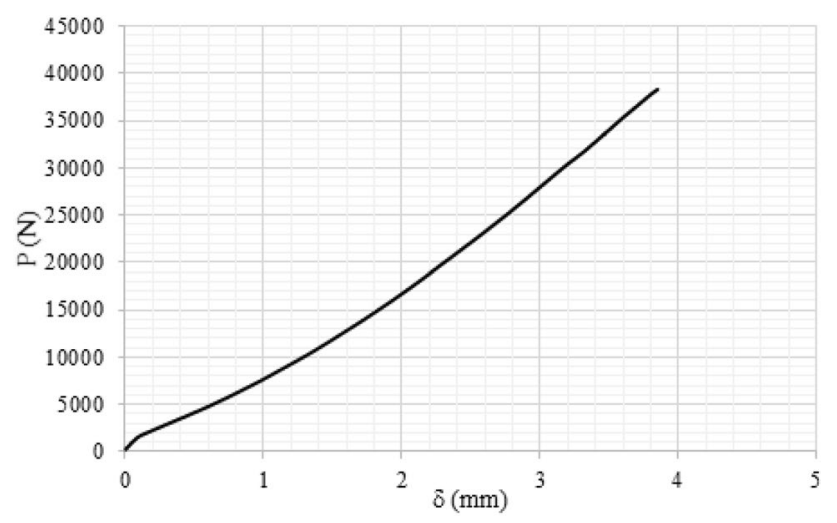

Fig. 3 Load-deformation curve of a non-aged specimen

Table 2 Results for the static tensile tests

\begin{tabular}{llrlr}
\hline Property & $P_{\text {failure }}(\mathrm{N})$ & $\mathrm{CoV}(\%)$ & $\delta_{\text {failure }}(\mathrm{mm})$ & $\mathrm{CoV}(\%)$ \\
\hline Non-aged & 38,930 & 12.82 & 3.952 & 10.21 \\
$75^{\circ} \mathrm{C}$ for 1 week & 40,372 & 13.12 & 4.087 & 9.27 \\
$75^{\circ} \mathrm{C}$ for 2 weeks & 46,373 & 5.18 & 4.540 & 3.37 \\
\hline
\end{tabular}

converts into shear within the adhesive layer) at a frequency of $10 \mathrm{~Hz}$. The maximum magnitude of the force was set to a value of $14.5 \mathrm{kN}$ which is sufficiently far from the values of the maximum force at fracture measured in the previous section under static loading (38.93 $\mathrm{kN} \pm$ $12.81 \%$ for non-aged configuration; $40.372 \mathrm{kN} \pm 13.12 \%$ for 1 week ageing configuration; and $46.373 \mathrm{kN} \pm 5.18 \%$ for 2 weeks ageing configuration). Since the target of this section was a thermal ageing influence and not a fatigue characterization, this maximum load value was chosen to give moderate life cycles as output (neither too high nor too low). The load ratio is equal to 0.1 ; thus, the axial tensile fatigue loading was oscillating between 1.45 and $14.5 \mathrm{kN}$. A hydraulic tensile/compression fatigue machine Schenck PSB with a load cell of $100 \mathrm{kN}$ was used to carry out the fatigue tests. The number of cycles to fracture under the mentioned conditions was recorded. Figure $4 a$ shows a double lap joint specimen clamped on the fatigue test machine, while Fig. 4b shows a fractured specimen. Plates $A$ and $C$ represent the outer adherents, while the plate $B$ is the central adherent. The surface shown of the plate $B$ matches the surface of the plate $C$, while the back surface of the plate $B$ (not shown) matches the surface of 
Fig. 4 a Specimen under fatigue testing and $\mathbf{b}$ fractured specimen

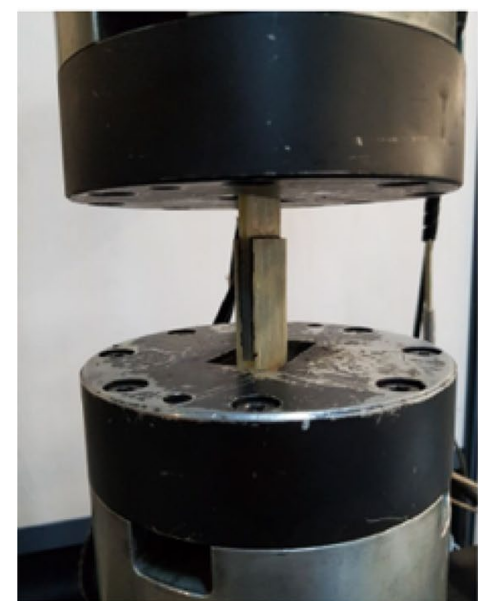

(a)

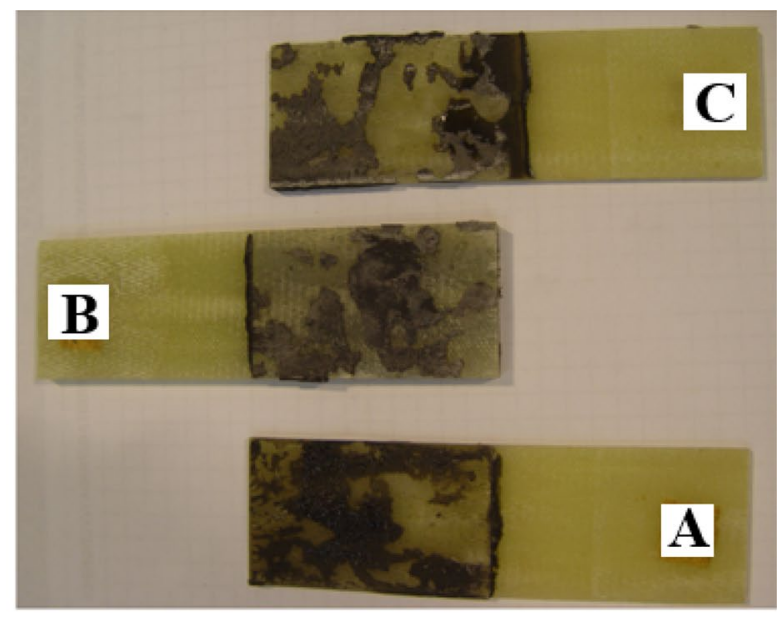

(b)
Table 3 Results of fatigue tests

\begin{tabular}{llll}
\hline Ageing type & $P_{\max }(\mathrm{kN})$ & $N_{\text {fcycles }}$ & St. Dev. (\%) \\
\hline Non-aged & 14.5 & 321,425 & 16.76 \\
$75^{\circ} \mathrm{C}$ for 1 week & 14.5 & 487,564 & 15.47 \\
$75^{\circ} \mathrm{C}$ for 2 weeks & 14.5 & 644,674 & 12.30 \\
\hline
\end{tabular}

the plate $A$. Figure $4 \mathrm{~b}$ illustrates a partially adhesive failure: the adhesive layer has not remained as one entity completely stuck at one of the substrates. The adhesive joint has been torn apart, and hence, the separation has not occurred completely at the interface adhesive-adherent. However, one could notice that many small regions within the fractured areas are adhesive-free. Some small adhesive parts that have been torn were still completely attached to one of the substrates.

This type of failure was observed for the three thermal ageing configurations.

Thermal ageing configurations. Table 3 summarizes the average number of cycles to failure along it should be noticed that similar fracture aspect was observed on similar specimens tested under static loading in the previous section and this for the same with the corresponding standard deviation assigned to each configuration of thermal ageing.

\subsection{Adhesive testing}

Unlike the majority (but not the totality) of the results obtained in the literature for the different configurations of thermal ageing adopted, it was found an improvement in the static shear strength with ageing duration when a short-time thermal ageing was applied. Furthermore, same trend for the fatigue life was obtained. Following the mechanical tests carried out on the DLJ assemblies, the

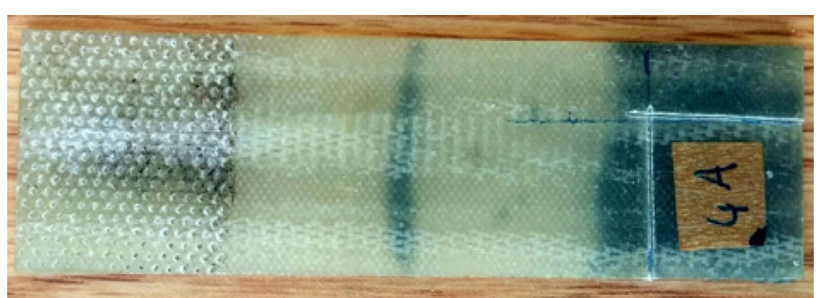

Fig. 5 Square of $2 \times 2 \mathrm{~cm}^{2}$ cut for SEM testing

obtained results have urged to conduct further investigations on the status of adhesive Araldite 2031 existing in the fractured specimens in order to explain the tendency of the obtained results.

As a first step, a SEM analysis of the adhesive-substrate interface of fractured specimens for the three ageing configurations was carried out. Since the specimen holder of the SEM set-up is able to support small dimensions specimens, small pieces of $2 \times 2 \mathrm{~cm}^{2}$ were cut from the fractured interfaces; they were obviously chosen in regions where adherents were still carrying adhesive layer in order to examine the status of the adhesive (Fig. 5). Observations were conducted on pieces picked up from specimens corresponding to the three different thermal ageing configurations. The parts $a, b$ and $c$ of Fig. 6 show the difference of surface morphologies from one type of ageing to the other. Further discussions about those observations will be detailed in the coming section. Due to those differences of surface morphologies, a further couple of thermal analyses for the adhesive picked up from the fractured interfaces of the assemblies were found indispensable.

For this purpose, small amounts from the adhesive at the aforementioned interfaces belonging to the three types of ageing were picked up and subjected to three types of thermal testing: 


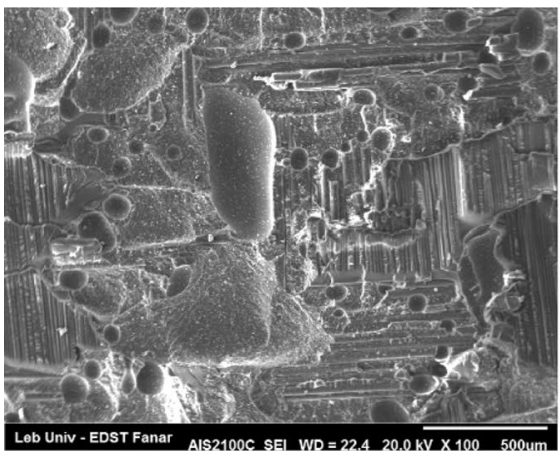

(a)

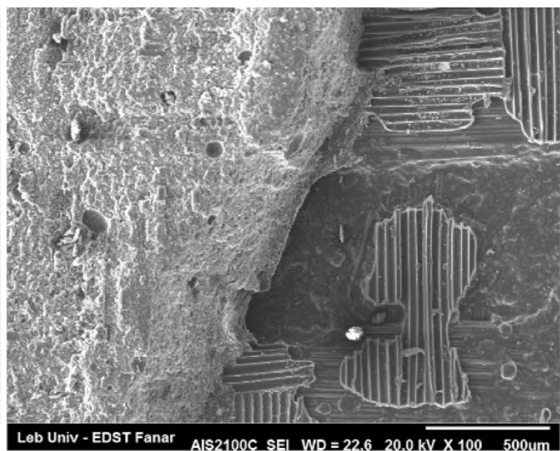

(b)

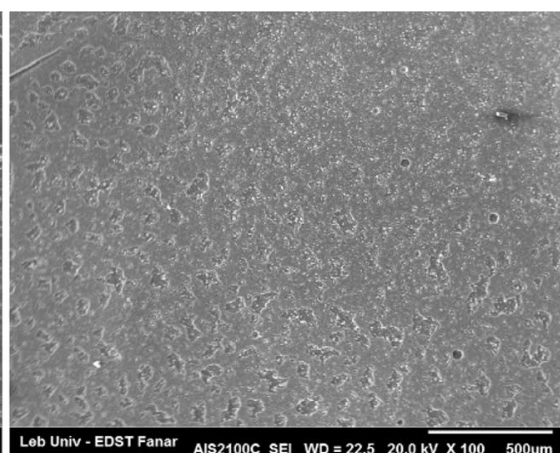

(c)

Fig. 6 Couple of tests on the adhesive after tensile tests; a SEM of non-aged sample, b SEM of thermally aged at $75^{\circ} \mathrm{C}$ for 1 week and $\mathbf{c}$ SEM of thermally aged at $75^{\circ} \mathrm{C}$ for 2 weeks

- Thermogravimetric analysis (TGA) to examine the degradation of the adhesive. The machine used for those tests is a NETZSCH TG 209 F3 Tarus model in accordance with ASTM E1131-08 standard procedure [20]. The amount of adhesive tested was varying from 6 to $7 \mathrm{mg}$. Tests were carried out in a nitrogen ambiance at a rate of $20 \mathrm{ml} / \mathrm{min}$. A temperature sweep from $30{ }^{\circ} \mathrm{C}$ till $900{ }^{\circ} \mathrm{C}$ was adopted at a rate of $10^{\circ} \mathrm{C} / \mathrm{min}$. At each point, the remaining mass percentage as well as the rate of mass degradation were recorded. All the recorded graphs are illustrated in Figs. 7a, b, c that correspond to the non-aged, 1-week aged and 2-weeks aged specimens, respectively. It should be noticed that TG (left ordinate axis) represents the percentage of mass loss (thermogravimetry) while DTG (right ordinate axis denotes for differential thermogravimetry) represents the rate of this loss (percentage per unit time, here the time is in minutes).

- Differential scanning calorimetry (DSC) to investigate the thermal behaviour of the adhesive which might lead to some conclusions about its morphological stability. The machine adopted for this purpose is a NETZCH DSC Polyma 214 according to ASTM D3418 standard [21]. A temperature sweep from $30{ }^{\circ} \mathrm{C}$ till $300^{\circ} \mathrm{C}$ was adopted at a rate of $10^{\circ} \mathrm{C} / \mathrm{min}$ in a nitrogen ambiance to avoid oxidation of the adhesive during the test. The reverse path was always carried out (cooling from $300^{\circ} \mathrm{C}$ till $30^{\circ} \mathrm{C}$ ). At each point, the enthalpy per unit mass is recorded. Upon the sign of the enthalpy, the process could be either exothermal or endothermal. All the recorded graphs are illustrated in Figs. 8a, $\mathrm{b}, \mathrm{c}$ that correspond to the non-aged, 1-week aged and 2-weeks aged specimens, respectively.

- Fourier transform infrared spectroscopy (FTIR) to check the oxidation phenomenon within the adhesive. The corresponding set-up is a Bruker tensor II spectrometer operated in attenuated total reflectance (ATR) mode according to the ASTM E1252 [22]. Small fragments of the adhesive were hermetically enclosed into corresponding capsules and subjected to infrared radiations. Intensity of infrared ray absorbance by the material is recorded along an interval of wave numbers or frequencies. Upon the chemical groups existing in the morphology of the specimen, peak of absorbance will be observed at the corresponding resonant frequencies or wave numbers characterizing the different existing groups. The oxidation is characterized by the carbonyl group having a wave number of $1715 \mathrm{~cm}^{-1}$. All the recorded graphs are illustrated in Figs. 9a, b, c that correspond to the non-aged, 1-week aged and 2-weeks aged specimens, respectively.

\section{Results and discussion}

The results obtained in Table 2 show that the static shear strength increases with the ageing duration, while Table 3 shows similar tendency for fatigue life. Values in Table 2 and 3 show that the average static force at failure and number of cycles to failure, respectively, increase with the period of ageing, hence the increase in fracture resistance. Under static loading, the specimens kept at the ambient temperature have failed at an average static force of $38.93 \mathrm{kN}$, while the specimens aged at $75^{\circ} \mathrm{C}$ for 1 week have fractured at $40.372 \mathrm{kN}$ as average which corresponds to $3.7 \%$ of strength increment. For 2-weeks aged specimens, the average force to failure was measured as $46.373 \mathrm{kN}$, an improvement of $19 \%$ compared to the nonaged specimens. Under cyclic loading, the specimens kept at the ambient temperature have failed after an average of 321,425 cycles, while the specimens aged at $75^{\circ} \mathrm{C}$ for 1 week have fractured after 487,564 cycles as average 
Fig. 7 TGA curves for a nonaged specimens, $\mathbf{b} 1$ week at $75^{\circ} \mathrm{C}$ aged specimens and $\mathrm{c}$ 2 weeks at $75^{\circ} \mathrm{C}$ aged specimens
TG $/ \%$

DTG $/(\% / \mathrm{min})$

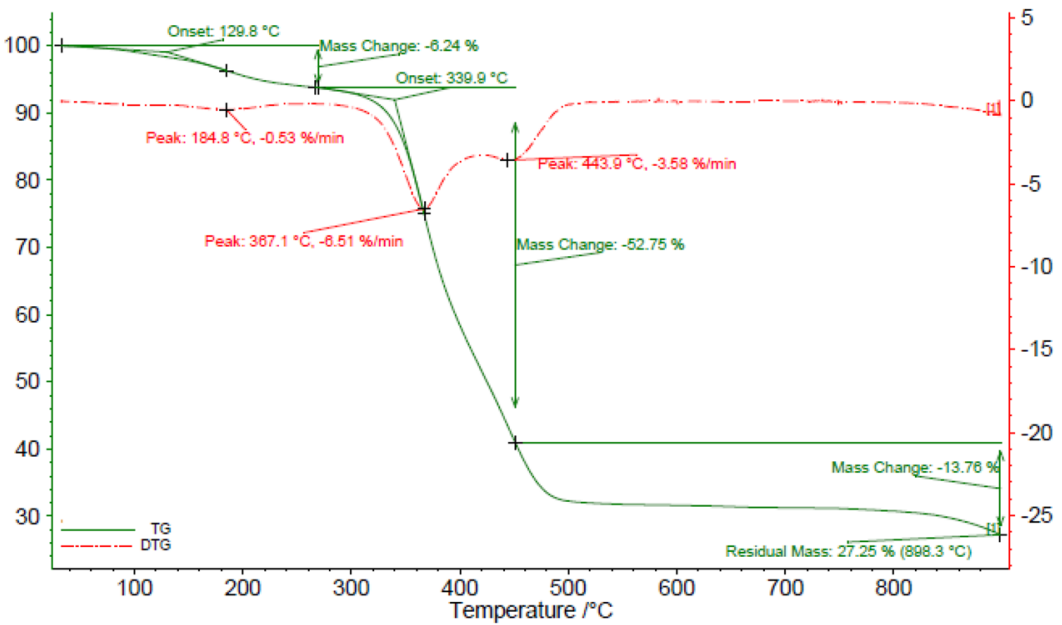

(a)

TG $/ \%$

DTG $/(\% / m i n)$

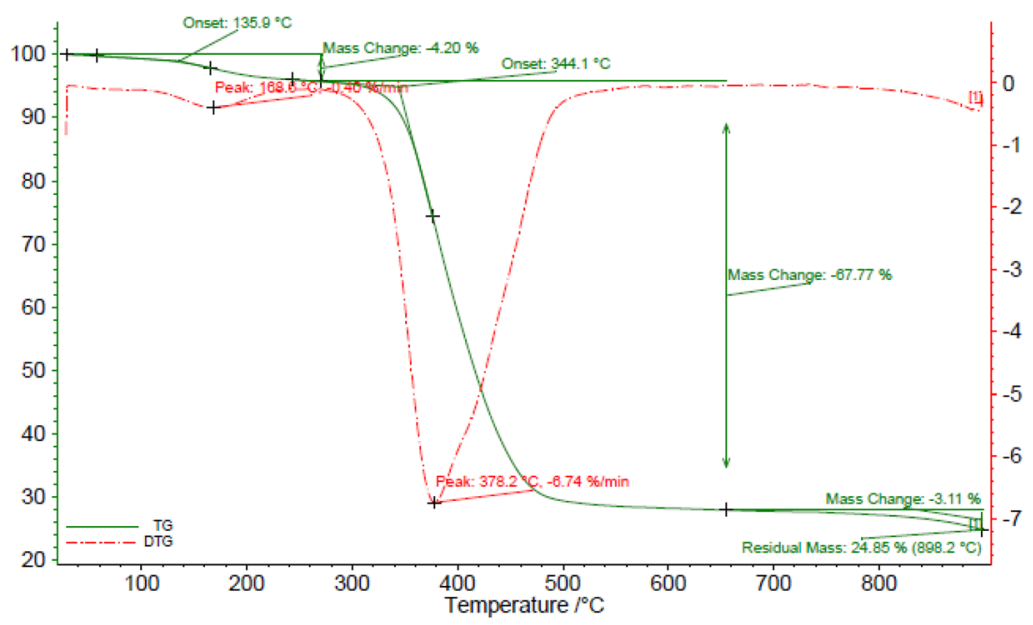

(b)

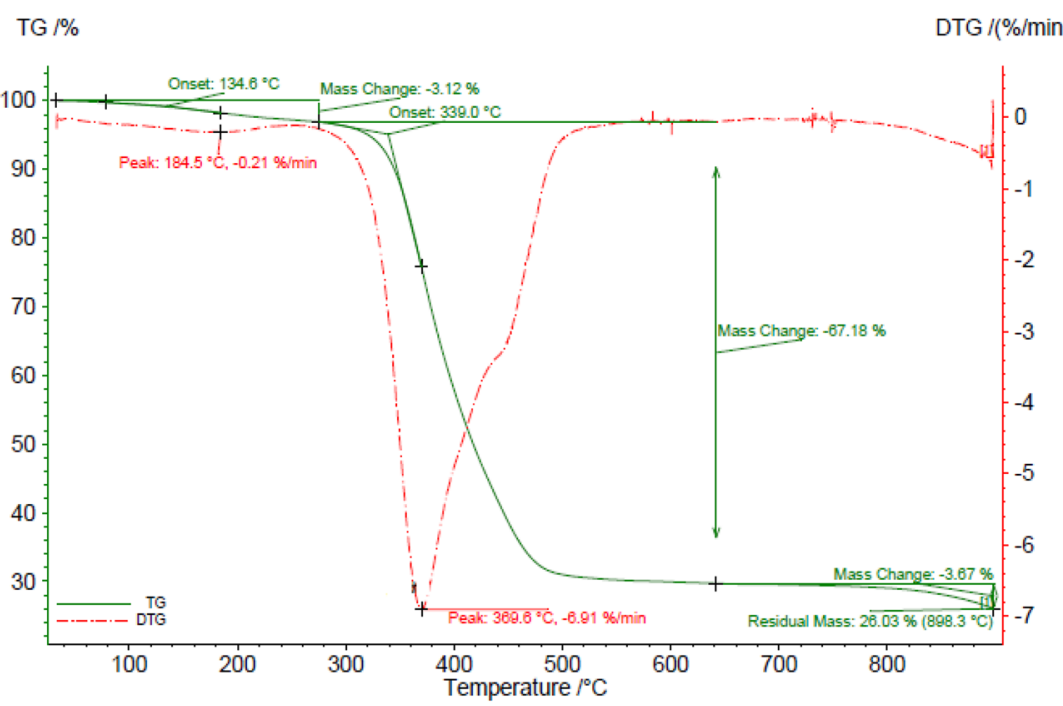

(c) 
Fig. 8 DSC curves for a nonaged specimens, $\mathbf{b} 1$ week at $75^{\circ} \mathrm{C}$ aged specimens and $\mathrm{c}$ 2 weeks at $75^{\circ} \mathrm{C}$ aged specimens

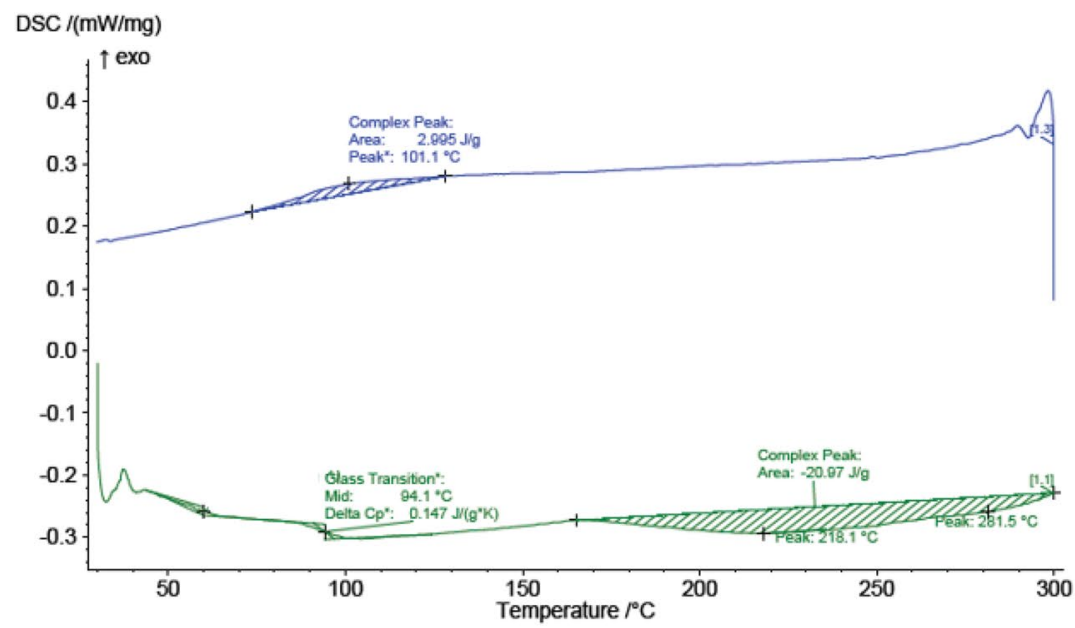

(a)

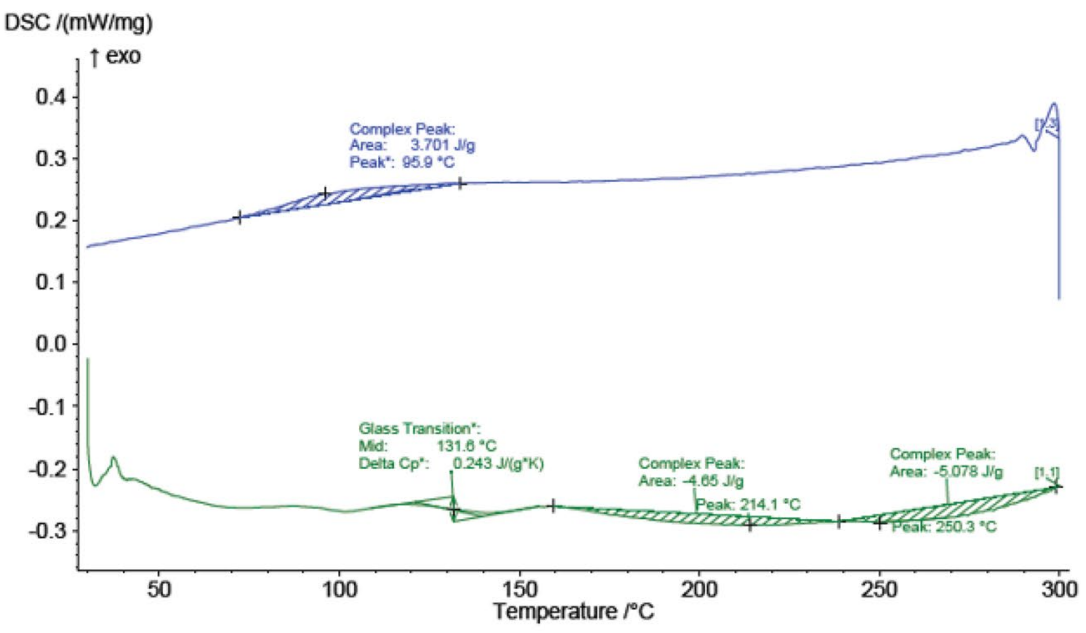

(b)

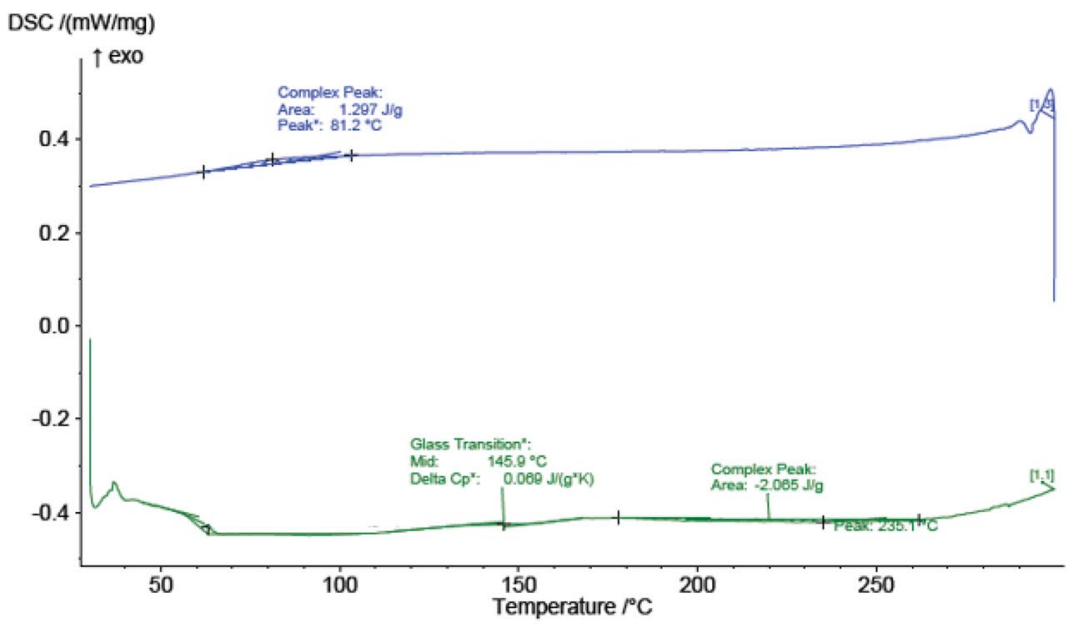

(c) 
Fig. 9 FTIR curves for a nonaged specimens, $\mathbf{b} 1$ week at $75^{\circ} \mathrm{C}$ aged specimens and $\mathrm{c}$ 2 weeks at $75^{\circ} \mathrm{C}$ aged specimens

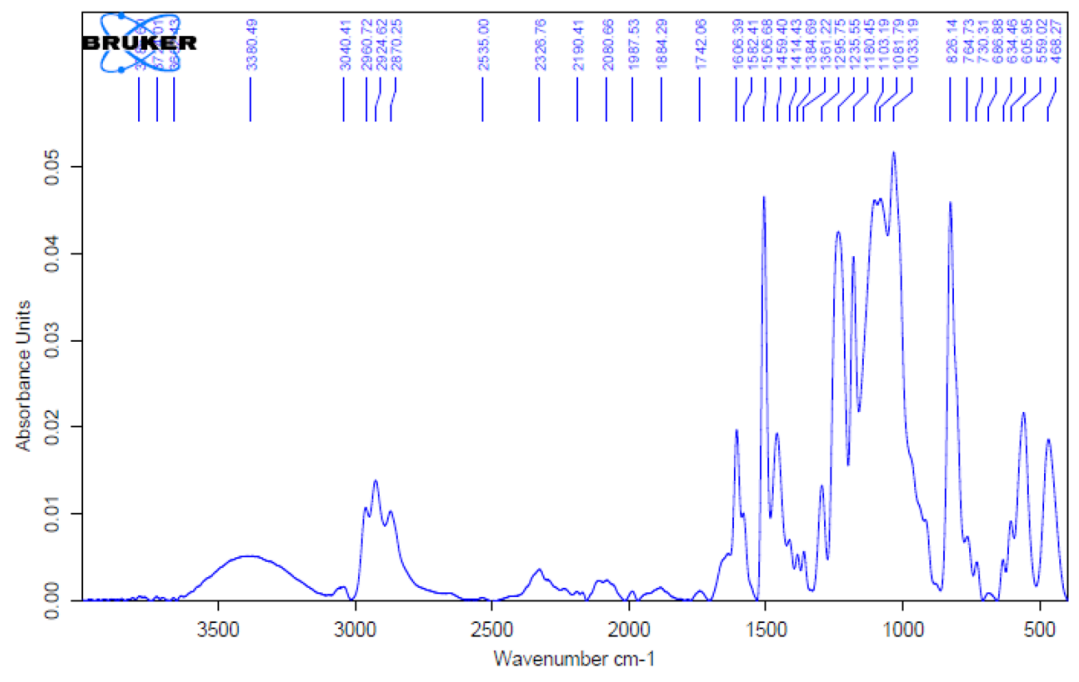

(a)

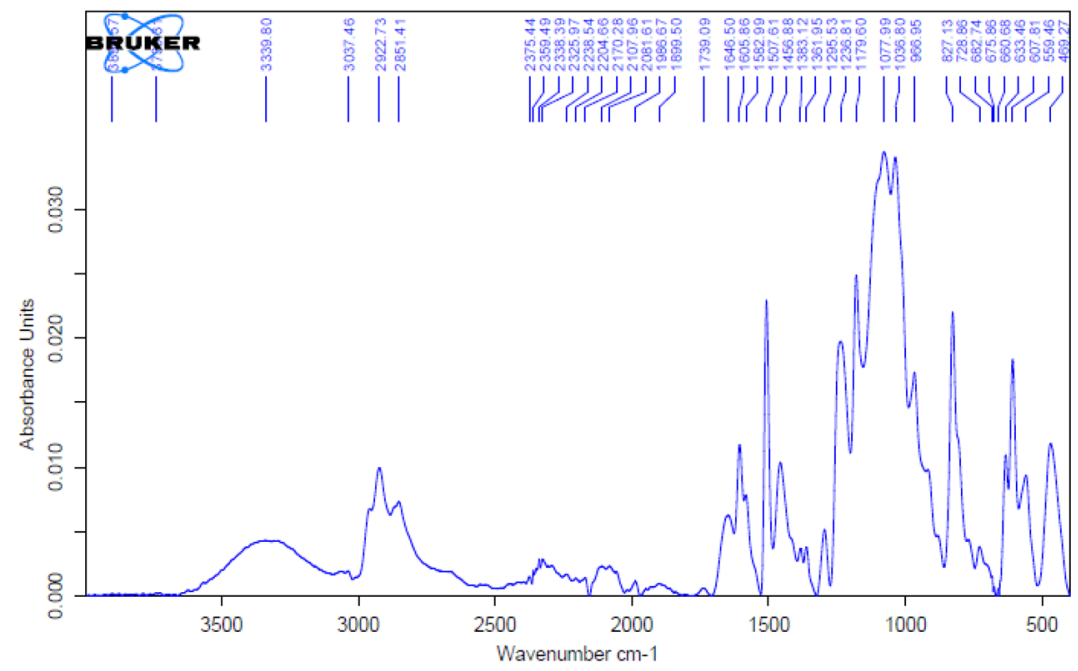

(b)

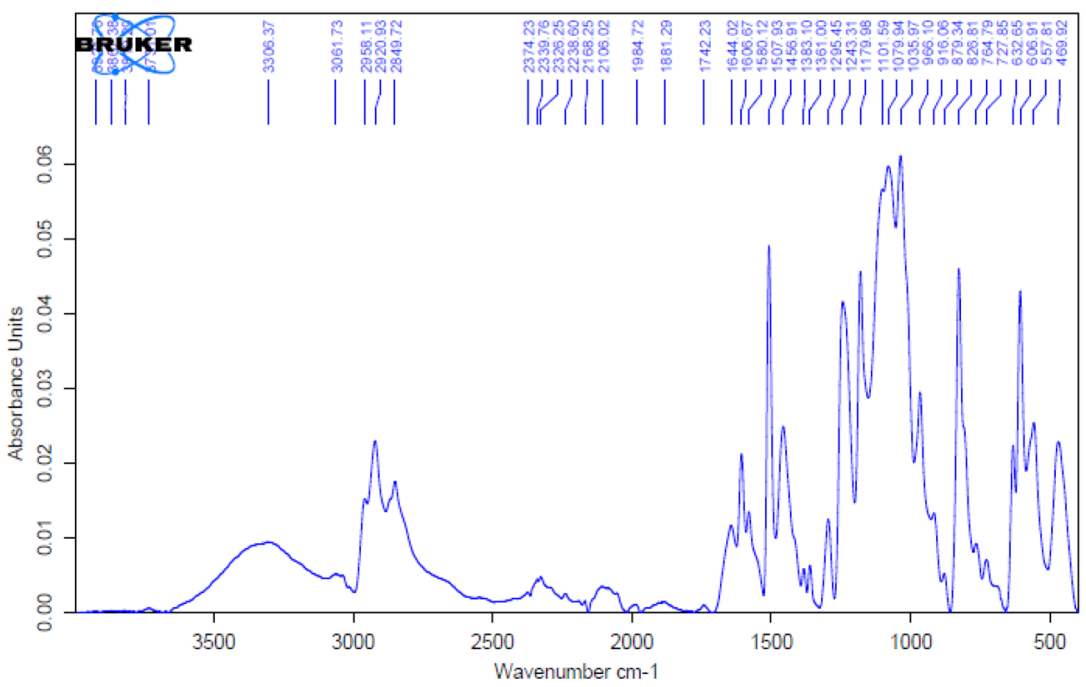

(c) 
which corresponds to $52 \%$ of life increment. For 2-weeks aged specimens, the average life was measured as 644,674 cycles, an improvement of $100 \%$ compared to the nonaged specimens.

Although the recorded results follow an opposite evolution to the majority of the findings in previous works, some of them cited in the present paper, the literature offers also couple of works where similar tendency to the actual results has been established. In the work of Fernandes et al. [14], carbon-epoxy composites were bonded using Araldite 2015 epoxy adhesive and aged for 3 months under $0{ }^{\circ} \mathrm{C}, 25^{\circ} \mathrm{C}$ and $50^{\circ} \mathrm{C}$ temperatures. It has been found that under mode II test, the fracture energy and the local strength increase slightly with the temperature increase. Hu et al. [23] have tested thermally aged single lap joints under quasi-static tensile loading using three different epoxy adhesives: Loctite ESP 110, Araldite AV 138 and Araldite 2015. The ageing duration was one week under three different temperatures: $-30^{\circ} \mathrm{C}, 25^{\circ} \mathrm{C}$ and $80^{\circ} \mathrm{C}$. The latter two temperatures have exhibited almost the same peak load for the first two aforementioned adhesives, while Araldite 2015 has shown the highest peak load at $80^{\circ} \mathrm{C}$. For all three adhesives, the lowest peak load values were found to correspond to the $-30^{\circ} \mathrm{C}$ temperature. Another work could be cited in this context where Turan [24] has tested non-aged and thermally aged glass-epoxy strap joints under tensile loading. The ageing temperatures have been $75^{\circ} \mathrm{C}, 100^{\circ} \mathrm{C}$ and $150^{\circ} \mathrm{C}$ while two ageing durations, 4 and $8 \mathrm{~h}$, have been adopted for each temperature. The peak loads have been found to increase from $28 \%$ up to $133 \%$ for the aged specimens over the unaged ones.

The couple of tests in Sect. 2.4 on the adhesive picked up from the fractured specimens under different configurations of ageing were carried out to justify the results in Table 2 and 3.

The images $a, b$ and $c$ of Fig. 6 were treated using the software IMAGE $J$ to quantify the amounts of voids within the adhesive layer. It was clearly found that the non-aged adhesive interface contains a remarkable amount of voids (6\%) which reduces significantly the contact area between the adhesive and the composite substrates. This amount of voids is found to decrease within the 1-week aged adhesive interface $(2.15 \%)$ with respect to the non-aged adhesive which improves the contact area. The interface of the 2-weeks aged adhesive shows that voids have almost completely disappeared $(0.32 \%)$ and the contact area is smooth and optimal. Indeed, the adhesive was kept curing at the ambient temperature according to the data sheet [19]. Although a mechanical compression was applied during curing, this will not be sufficient to prevent formation of air bubbles. By increasing the temperature till $75^{\circ} \mathrm{C}$ which is above the $T_{\mathrm{g}}$ given in the data sheet by $10^{\circ} \mathrm{C}$, the macromolecular chains in the rubbery status of the polymer were forced to move and change their positions and their rearrangements within the space of the adhesive layer. During motion, those viscoelastic macromolecules will fill the locations of the air bubbles to remove them away. The period of 1 week at this temperature was not sufficient to remove the entire amount, while 2 weeks period has given the chains enough time to take away the majority of the voids. An excessive time of ageing would have given worst results by leading to the decomposition of the polymeric epoxy adhesive. Air bubbles removal using thermal effect was applied by Kumar et al. [25] who kept their cured epoxy resin in vacuum under $70^{\circ} \mathrm{C}$ temperature for $20 \mathrm{~min}$. According to the data sheet of the supplier [19], the cure cycle at the ambient temperature for $24 \mathrm{~h}$ was enough to complete the curing of the adhesive without any proposed post-curing process. Moreover, after the preparation, the specimens were kept many weeks under constant conditions before ageing; this long period of storage was separating between the preparation process at the ambient room and the ageing process. This was sufficient at this stage to give away the probability of a post-curing. Therefore, one can remark that the smoothness of the surface, ultimately the effective adhesion area, improves with the ageing duration; this yields to an increment in strength which reflects the obtained results under both fatigue and static loading. It is worth to remind that the main target of the present work is not to characterize an absolute behaviour under either static or fatigue or to establish S-N curves for the tested specimens; the main concern is to focus on the influence of the thermal ageing configuration on the static and fatigue response; thus, the only parameter that was changed along the whole work was exclusively the thermal ageing configuration while the loading conditions, the materials and the geometry were kept unchanged.

Furthermore, analyzing some remarkable and critical points in the graphs of Figs. 7, 8 and 9 in the coming lines will constitute a clear interpretation of the results obtained in Table 2 and 3:

- Graphs of Fig. 7 prove that the onset of decomposition of the adhesive epoxy Araldite 2031 occurs at temperatures above $130^{\circ} \mathrm{C}$ for the three types of ageing with a maximum mass loss percentage of about $6 \%$. Moreover, the temperature corresponding to the maximum rate of decomposition lies in an interval of $370^{\circ} \mathrm{C}-378^{\circ} \mathrm{C}$. All those critical temperatures are hugely far from the ageing temperature of $75^{\circ} \mathrm{C}$ adopted in the actual work; therefore, the adhesive has not degraded under any of the three ageing configurations adopted in this study.

- Graphs of Fig. 8 lead to conclude about an improvement in morphological stability of the adhesive along 
with the ageing duration. Indeed, for the three graphs $\mathrm{a}, \mathrm{b}$ and $\mathrm{c}$, one can remark that at about $63^{\circ} \mathrm{C}$, a first stage of thermal stabilization occurs ending a transient behaviour zone observed at the beginning of the test; this might correspond to the glass transition temperature of $65^{\circ} \mathrm{C}$ stated in [19]. However, the recorded graphs show a more significant transition point that appears later on each curve corresponding to the effective transition temperature values. In Fig. 8a, the value of $94{ }^{\circ} \mathrm{C}$ was recorded; however, a significant melting area of about $21 \mathrm{~J} / \mathrm{g}$ was also noticed; thus, the adhesive was completing its thermal stabilization during the test; it should be noticed that the adhesive is a mixture of a resin and a hardener; this might complicate the behaviour. The 1 -week aged adhesive exhibits a $132^{\circ} \mathrm{C}$ glass transition temperature with slight melting areas which show a better stability than the previous ageing case while the 2-weeks aged adhesive exhibits an increase in $T_{\mathrm{g}}$ that reaches $146{ }^{\circ} \mathrm{C}$ with always narrow melting zones which implies classifying it as the most morphologically stable adhesive among the three configurations. Those observations are able to spot on that the cure cycle in [19] is a general cycle applied for a global use; however, upon ageing and due to the existence of two components in this epoxy, the crosslinking of the macromolecular chains occurs in stages. By increasing the temperature and keeping it for 1 week, a supplementary amount of chains the thermoset adhesive have reached their crosslinking has led to an increment of $T_{\mathrm{g}}$. By keeping the ageing temperature for one additional week, almost the totality of the remaining moving chains have reached their crosslinking; this was revealed by an increment of $T_{\mathrm{g}}$. At this stage and taking in account the initial cure cycle in the data sheet [19] and the quite long period of storage of the specimens before heating and then before testing, the tendency was to apply a thermal ageing on the specimens and not a post-curing. However, the thermal behaviour and the morphology of the Epoxy Araldite 2031 adhesive have shown that this thermal ageing was beneficial and has led to a crosslinking completion and stability improvement.

- Graphs of Fig. 9 show the absence of peak of absorbance at the resonant wave number of $1715 \mathrm{~cm}^{-1}$, and this is true for all ageing configurations, and hence, the absence of carbonyl group in the macromolecular structure of the adhesive could be confirmed which means that the adhesive has not oxidized during any of the adopted ageing types.

Combining all the results of SEM, TGA, DSC and FTIR tests, one could conclude that for this specific type of epoxy and exclusively for those three thermal ageing configurations, the 2-week aged specimens exhibit the best static strength and fatigue life. Going beyond 2 weeks at $75^{\circ} \mathrm{C}$ or going beyond $75^{\circ} \mathrm{C}$ always at 2 weeks will not guarantee any extension of the established results and will not allow to predict any further results. New experimental campaigns must be conducted once any condition is changed.

\section{Conclusion}

Short-period thermal ageing was applied on DLJ glass-epoxy composites to examine its influence on the shear static strength and fatigue life under $14.5 \mathrm{kN}$ amplitude axial force. Three ageing configurations were adopted: ambient temperature: $75{ }^{\circ} \mathrm{C}$ at 1 week and 2 weeks. The glass transition temperature of the Araldite 2031 epoxy according to the supplier's data sheet is $65^{\circ} \mathrm{C}$; the ageing temperature was chosen to be $10^{\circ} \mathrm{C}$ above the glass transition temperature. It was found that both static shear strength and fatigue life improve, respectively, by $3.7 \%$ and $52 \%$ for 1 -week ageing and by $19 \%$ and $100 \%$ for 2-weeks ageing. For further investigations, the SEM analysis has shown the increment of the contact surface adherent-adhesive with the increment of the ageing period. The higher quality of contact area leads to reduce the stress intensification factors; therefore, the fracture resistance of the joint increases. Thermal tests on the adhesive picked up from the fractured specimens have shown the absence of degradation and oxidation for any case of ageing; however, the 2-weeks aged adhesive possesses the most stable morphology. All those observations present a convincing justification of the mechanical behaviour improvement.

Acknowledgements The authors would like to acknowledge some national institutions that were cooperative to achieve this work successfully: Faculty of Sciences of the Lebanese University; INDEVCO Group, Notre Dame University and Balamand University.

\section{Compliance with ethical standards}

Conflict of interest The authors declare that there are not potential conflicts of interest with respect to research, authorship and publication of this article.

\section{References}

1. Yokozeki T, Ishibashi M, Kobayashi Y et al (2016) Evaluation of adhesively bonded joint strength of CFRP with laser treatment. Adv Comps Mater 25(4):317-327

2. Zeaiter A, Challita G, Khalil K (2019) Investigation of vibration modes of a double-lap bonded joint. SN Appl Sci. https://doi. org/10.1007/s42452-019-0340-8 
3. Kim M, Kim H, Lee W (2015) Repair of aircraft structures using composite patches bonded through induction heating. Adv Comps Mater 24(4):307-323

4. Heshmati M, Haghani R, Al-Emrani M (2017) Durability of bonded FRP-to-steel joints: effects of moisture, de-icing salt solution, temperature and FRP type. Compos Part B Eng 119:153-167

5. Stazi F, Giampaoli M, Rossi M et al (2015) Environmental ageing on GFRP pultruded joints: comparison between different adhesives. Compos Struct 133:404-414

6. Nguyen TC, Bai Y, Zhao XL et al (2011) Mechanical characterization of steel/CFRP double strap joints at elevated temperatures. Compos Struct 93:1604-1612

7. Agarwal A, Foster SJ, Hamed E (2016) Testing of new adhesive and CFRP laminate for steel-CFRP joints under sustained loading and temperature cycles. Compos Part B Eng 99:235-247

8. Jeong MG, Kweon JH, Choi JH (2013) Effect of various hygrothermal environments on the failure of adhesively composite single-lap joints. J Comps Mater 47:2061-2073

9. Akderya T, Kemiklioğlu U, Sayman O (2016) Effects of thermal ageing and impact loading on tensile properties of adhesively bonded fibre/epoxy composite joints. Compos Part B Eng 95:117-122

10. Machado JJM, Marques EAS, Da Silva LFM (2018) Mechanical behavior of adhesively bonded composite single lap joints under quasi-static and impact conditions with variation of temperature and overlap. J Comps Mater 52:3621-3635

11. Wang M, Liu A, Liu Z et al (2013) Effect of hot humid environmental exposure on fatigue crack growth of adhesive-bonded aluminum A356 joints. Int J Adhes Adhes 40:1-10

12. Ashcroft IA, Hughes DJ, Shaw SJ et al (2001) Effect of temperature on the quasi-static strength and fatigue resistance of bonded composite double lap joints. J Adhes 75:61-88

13. Ferreira JAM, Reis PN, Costa JDM et al (2002) Fatigue behaviour of composite adhesive lap joints. Compos Sci Technol 62:1373-1379

14. Fernandes RL, De Moura MFSF, Moreira RDF (2016) Effect of temperature on pure modes I and II fracture behavior of composite bonded joints. Compos Part B Eng 96:35-44
15. Hu P, Han X, Da Silva LFM et al (2013) Strength prediction of adhesively bonded joints under cyclic thermal loading using a cohesive zone model. Int J Adhes Adhes 41:6-15

16. Zhang Y, Vassilopoulos AP, Keller T (2009) Environmental effects on fatigue behavior of adhesively-bonded pultruded structural joints. Compos Sci Technol 69:1022-1028

17. Sousa JM, Correia JR, Firmo JP et al (2018) Effects of thermal cycles on adhesively bonded joints between pultruded GFRP adherends. Compos Struct 202:518-529

18. Schneider B, Beber VC, Schweer J et al (2018) An experimental investigation of the fatigue damage behaviour of adhesively bonded joints under the combined effect of variable amplitude stress and temperature variation. Int J Adhes Adhes 83:41-49

19. Araldite 2031 datasheet (2016) HUNTSMAN advanced materials $\mathrm{GMBH}$

20. ASTM E1131-08. Standard test method for compositional analysis by thermogravimetry

21. ASTM D3418. Standard test method for transition temperatures and enthalpies of fusion and crystallization of polymers by differential scanning calorimetry

22. ASTM E1252. Standard practice for general techniques for obtaining infrared spectra for qualitative analysis

23. Hu P, Han X, Li WD et al (2013) Research on the static strength performance of adhesive single lap joints subjected to extreme temperature environment for automotive industry. Int J Adhes Adhes 41:119-126

24. Turan K (2019) Thermal aging effect on the failure loads of adhesively strap joints. J Compos Mater. https://doi. org/10.1177/0021998319846552

25. Kumar S, Samal SK, Mohanty S et al (2018) Bio-based tri-functional epoxy resin (TEIA) blend cured with anhydride (MHHPA) based cross-linker: thermal, mechanical and morphological characterization. J Macromol Sci Part A 55:496-506

Publisher's Note Springer Nature remains neutral with regard to jurisdictional claims in published maps and institutional affiliations. 